\title{
MODEL FOR PREDICTING FORMATION OF BAY BARRIER
}

Masumi Serizawa ${ }^{1}$ and Takaaki Uda

${ }^{1}$ Coastal Engineering Laboratory Co., Ltd., 301, 1-22 Wakaba, Shinjuku, Tokyo 160-0011, Japan

${ }^{2}$ Dr. Eng., Executive Director, Public Works Research Center, 1-6-4 Taito, Taito, Tokyo 110-0016, Japan

\section{INTRODUCTION}

A barrier island often develops along the marginal area of a flat shallow sea. Various explanations have been given for the cause of development of barrier islands. Most studies have focused on the development and deformation of a barrier island during increases in sea level in terms of the stratification of sand layers in the sand bar and the change in longitudinal profiles (Schwarz, 1971), and studies on the 3-D development of a barrier considering the water depth where the barrier island develops and wave intensity are rare. In this study, we consider the relationship between wave energy and the water depth where a barrier island develops, in which the wave energy reaching the shoreline is controlled under a constant-sea-level condition. On the basis of the results of a movable bed experiment by Uda et al. (1994), the development of a bay barrier is investigated using the BG model proposed by Serizawa et al. (2009), taking a bay barrier that extends deep in a bay as an example.

\section{MOVABLE-BED EXPERIMENT AND CALCULATION}

Uda et al. (1994) experimentally studied the mechanism by which a barrier can develop as an elongated sand spit through the action of longshore sand transport in a flat shallow sea. In their experiment, it was investigated whether or not a barrier is formed on a flat shallow sea under the condition that a sufficient volume of sand is supplied. A model beach was made of sand with $d_{50}=0.28$ $\mathrm{mm}$. The initial beach shape was set to be $V$-shaped. In the central part of the beach, a flat shallow sea bottom was made. The initial seabed slope was $1 / 5$ and the angle between the initial shoreline and wave direction was $45^{\circ}$. Regular waves with $H_{l}=3 \mathrm{~cm}(T=0.8$ s) were generated in the experiment. By changing the water depth of the flat shallow bottom $h_{s}$ to 7,5 and $3 \mathrm{~cm}$ (Cases 1,2 and 3 ), the relationship between the water depth of the flat shallow bottom of the bay and the formation of a bay barrier was investigated. Figures 2 (a), (b) and (c) show the beach topography of experimental results. In Case $2\left(h_{\mathrm{s}}=5 \mathrm{~cm}\right)$, a sand bar extended from both ends of the shallow flat sea toward the central part, forming a bay barrier. This barrier protruded in the central part, resulting in the protrusion of contours deeper than $6 \mathrm{~cm}$. A shallow sea was left behind the barrier, forming a lagoon. In case 3 $\left(h_{s}=3 \mathrm{~cm}\right)$, a barrier with a much wider lagoon was formed, leaving a shallow sea with a depth of $3 \mathrm{~cm}$. A sand spit rapidly elongated alongshore in the extremely shallow sea, forming a barrier with a lagoon behind it, when the ratio of the water depth to the equivalent wave height $(\gamma)$ was smaller than 1.7. But, no barriers are formed when $\gamma$ is larger than 2.3 as shown in case $1\left(h_{s}=7\right.$ $\mathrm{cm})$.

NUMERICAL MODEL : BG model proposed by Serizawa et al. (2009) and named after Bagnold's study

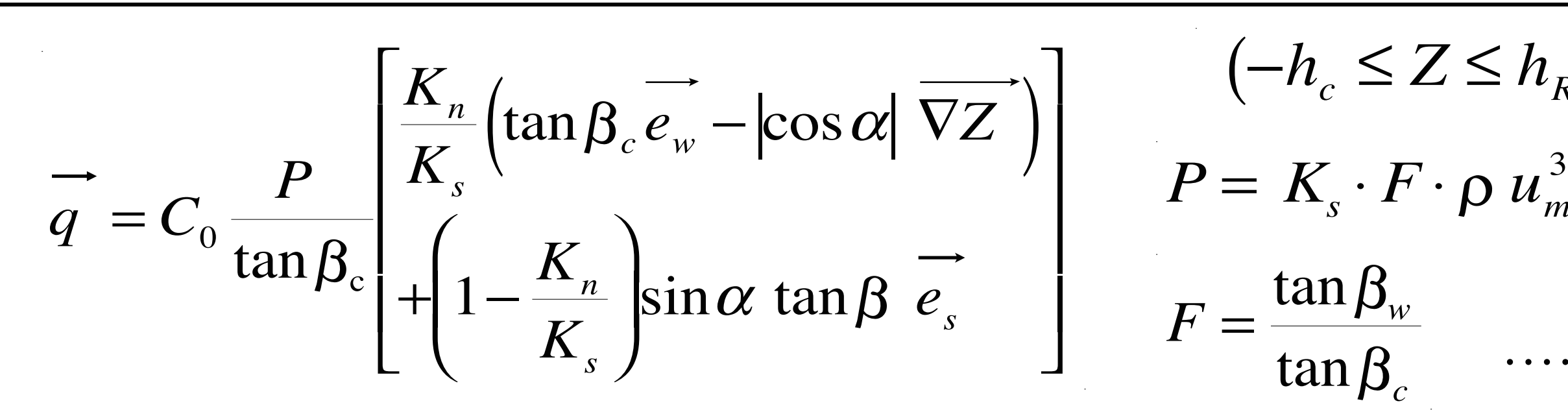

$\vec{q}=\left(q_{x}, q_{y}\right):$ sand transport flux, $Z=(x, y, t):$ seabed elevation, $\vec{e}_{s}:$ unit vector of wave direc tion, $\overrightarrow{e_{s}}$ : unit vector paral lel to contours, $u_{m}$ : orbital velocity of waves on seabed, $h_{c}$ : depth of closure, $h_{R}$ : berm height, $K_{s}$ and $K_{n}$ : coefficients of long shore and cross-shore sand transport, $\tan \beta$ : seabed slope, $\tan \beta_{c}$ : equilibrium slope, $\alpha$ : the angle between the wave direction and the normal to the contour line, $C_{0}$ : the coefficient by which the sand transport rate expressed by the weight of immersed sand is related to the volumetric sand transport rate, $\overrightarrow{\nabla Z}=(\partial Z / \partial x, \partial Z / \partial y), \tan \beta_{w}=\overrightarrow{e_{w}} \cdot \overrightarrow{\nabla Z}$

\section{- The wave field was calculated using the energy balance equation.}

- Space and time scales in the calculation are 100 and 10 -fold those in the experiment, respectively.

A shallow flat seabed initially extended at the head of the $\mathrm{V}$-shaped bay (Fig 3 (a)). When waves were incident from the y-direction, erosion started to occur near both ends, sand was transported to the central part of the bay and a sand spit began to form at each end of the flat shallow seabed (Fig. 3 (b)). These spits elongated with time and extended toward the central part after 3,000 steps (Fig. 3 (c)). After 4,000 steps, the sand spits were about to connect with each other (Fig. 3(d)). After 5,000 steps, a bay barrier was formed by the connection of the sand spits that developed in both directions (Fig. 3 (e)). Under the present condition, the shoreline receded at both ends, sand from both ends was continuously supplied to the central part and the bay barrier gradually increased in width over time. In contrast, landward of the bay barrier, a lagoon was left behind.

\section{CONCLUSIONS}

The formative mechanism of a bay barrier was clarified using the BG model, which was proposed by Serizawa et al. (2009) and named after Bagnold' s study.

- The predicted results were in good agreement with the experimental results of Uda et al. (1994)(Fig. 2)

- It was confirmed that the formation of a bay barrier is mainly due to the occurrence of wave breaking on the flat shallow bottom, from which a bay barrier extends. A barrier is formed under the condition that the ratio of the water depth of the flat shallow bottom to wave height $\gamma$ is smaller than 1.7 , but no barriers are formed when $\gamma$ is larger than 2.3 .

Experiment

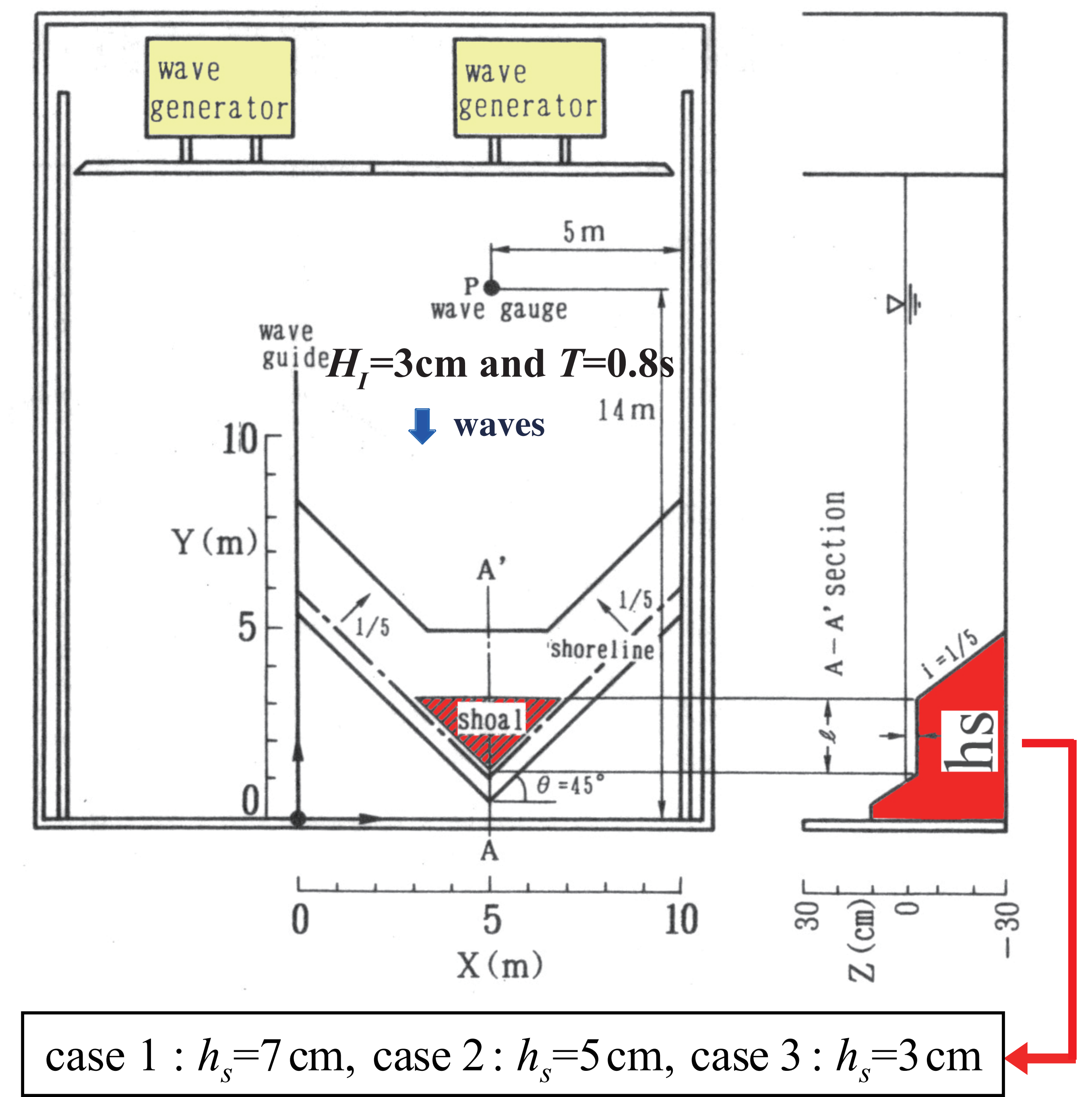

Fig. 1 Plane wave basin for movable bed experiment

\section{$\checkmark$ waves $H_{I}=3 \mathrm{~cm}$ and $T=0.8 \mathrm{~s}$}

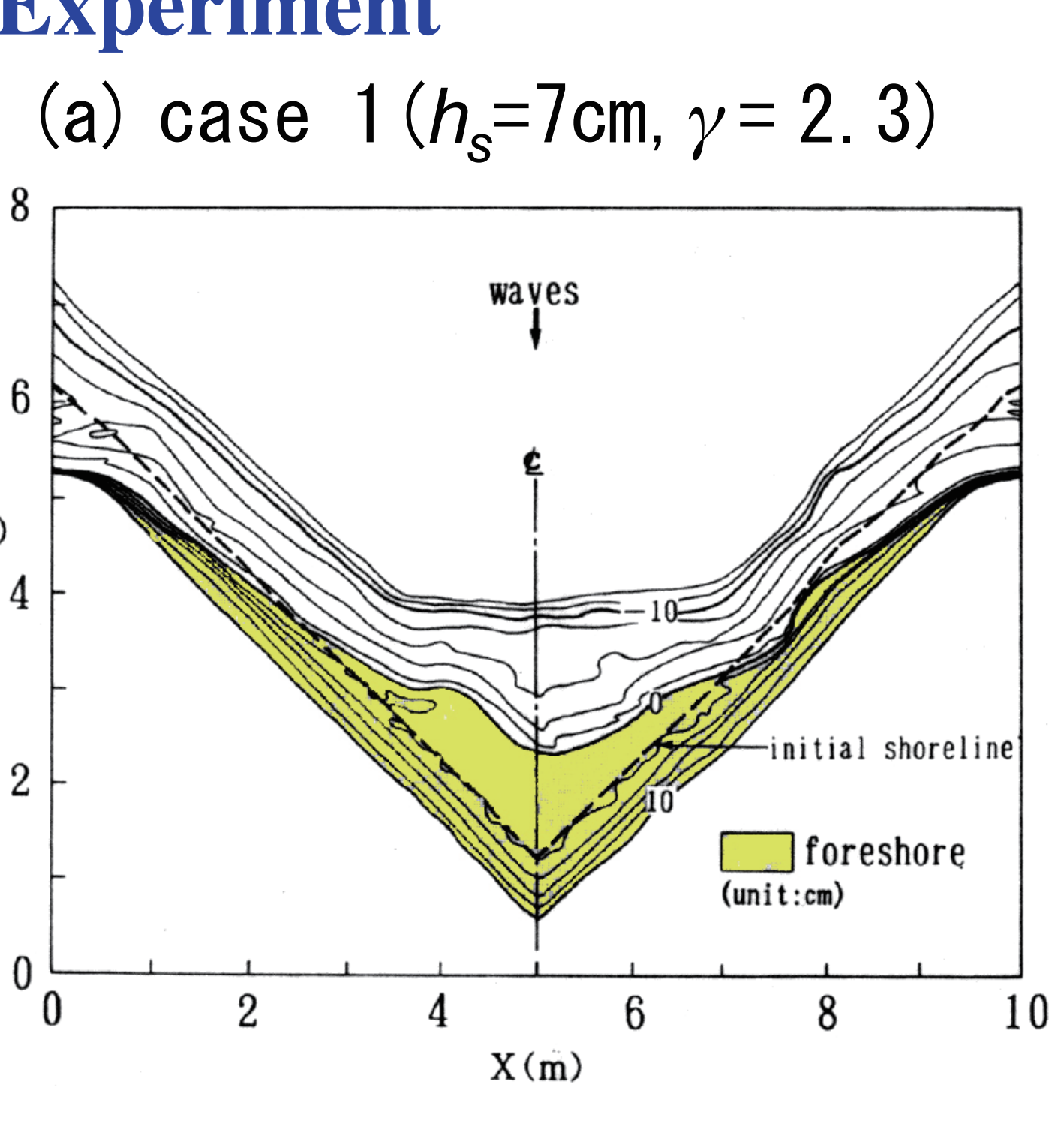

(b) case $2\left(h_{s}=5 \mathrm{~cm}, \gamma=1.7\right)$

(c) case $3\left(h_{s}=3 \mathrm{~cm}, \gamma=1.0\right)$

Numerical calculation
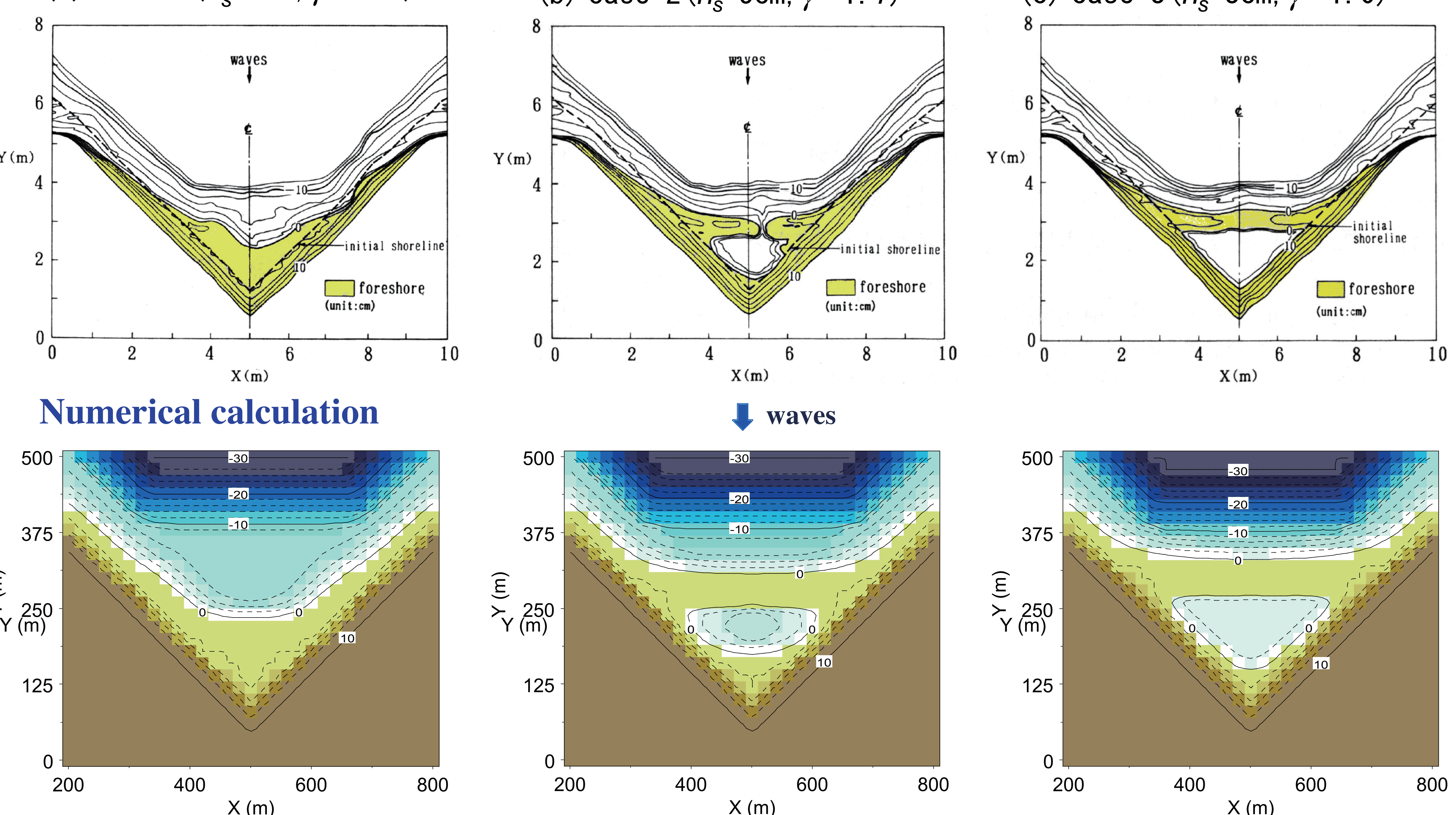

$\downarrow$ waves
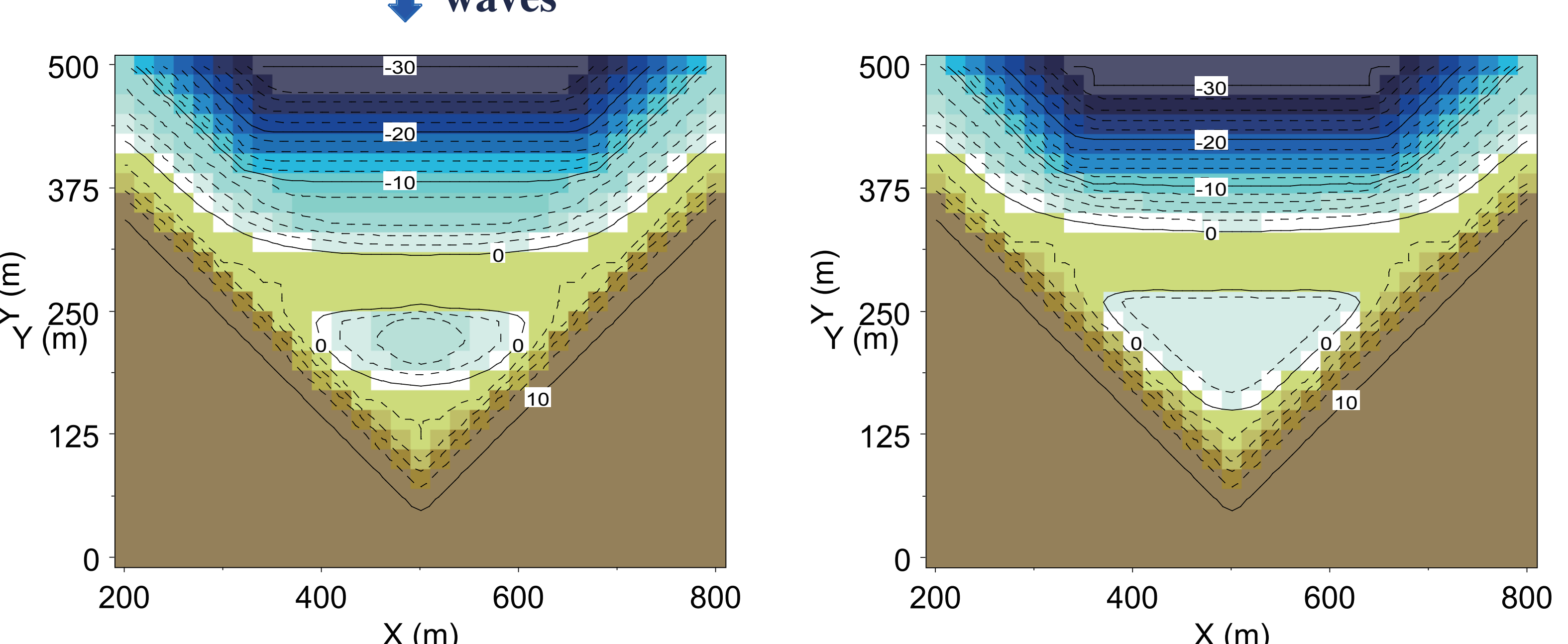

$200 \quad 400 \times(m) 600 \quad 800$

Fig. 2 Beach topography of experimental and predicted results

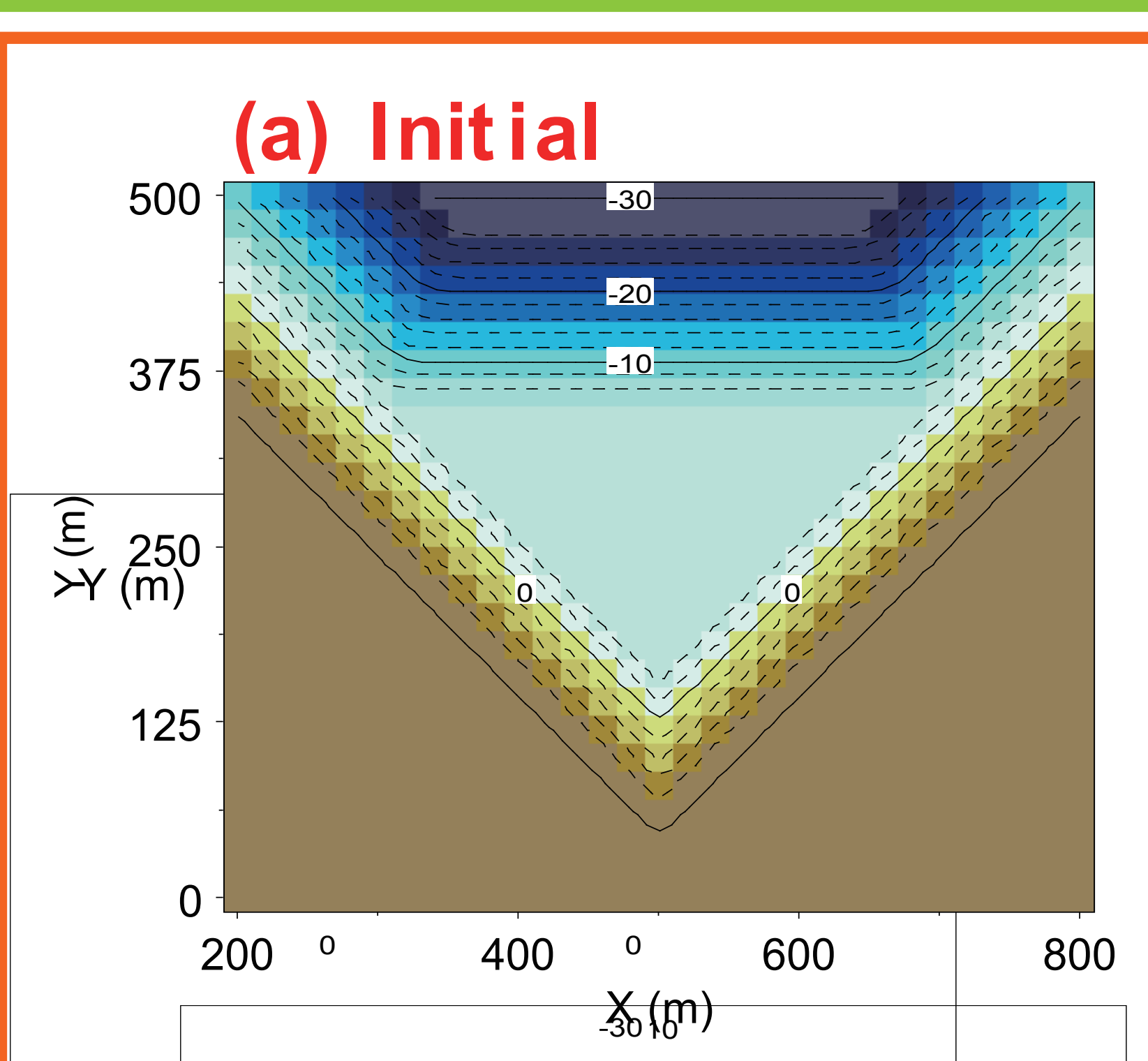

(d) 4000 steps

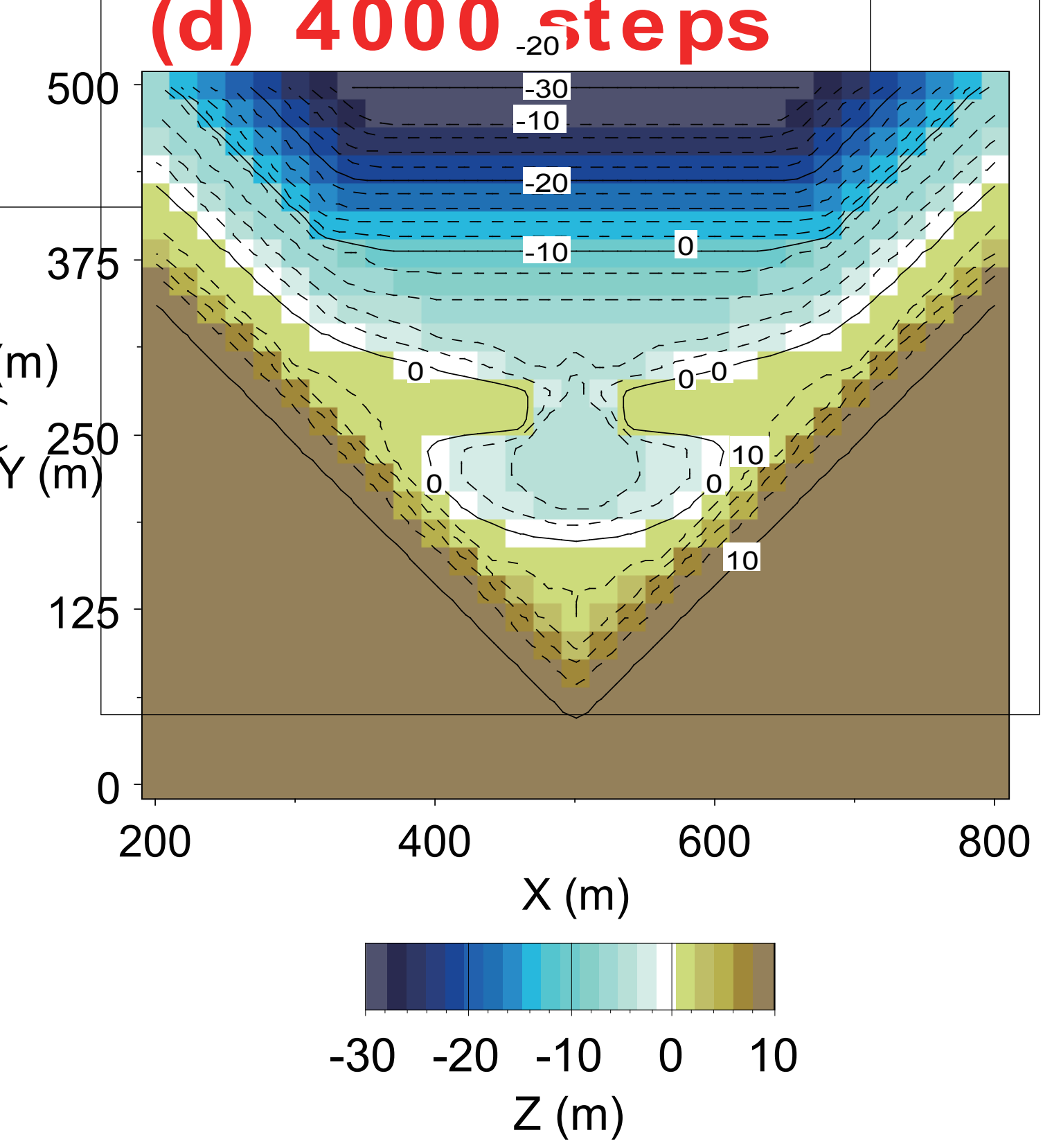

(b) 2000 steps

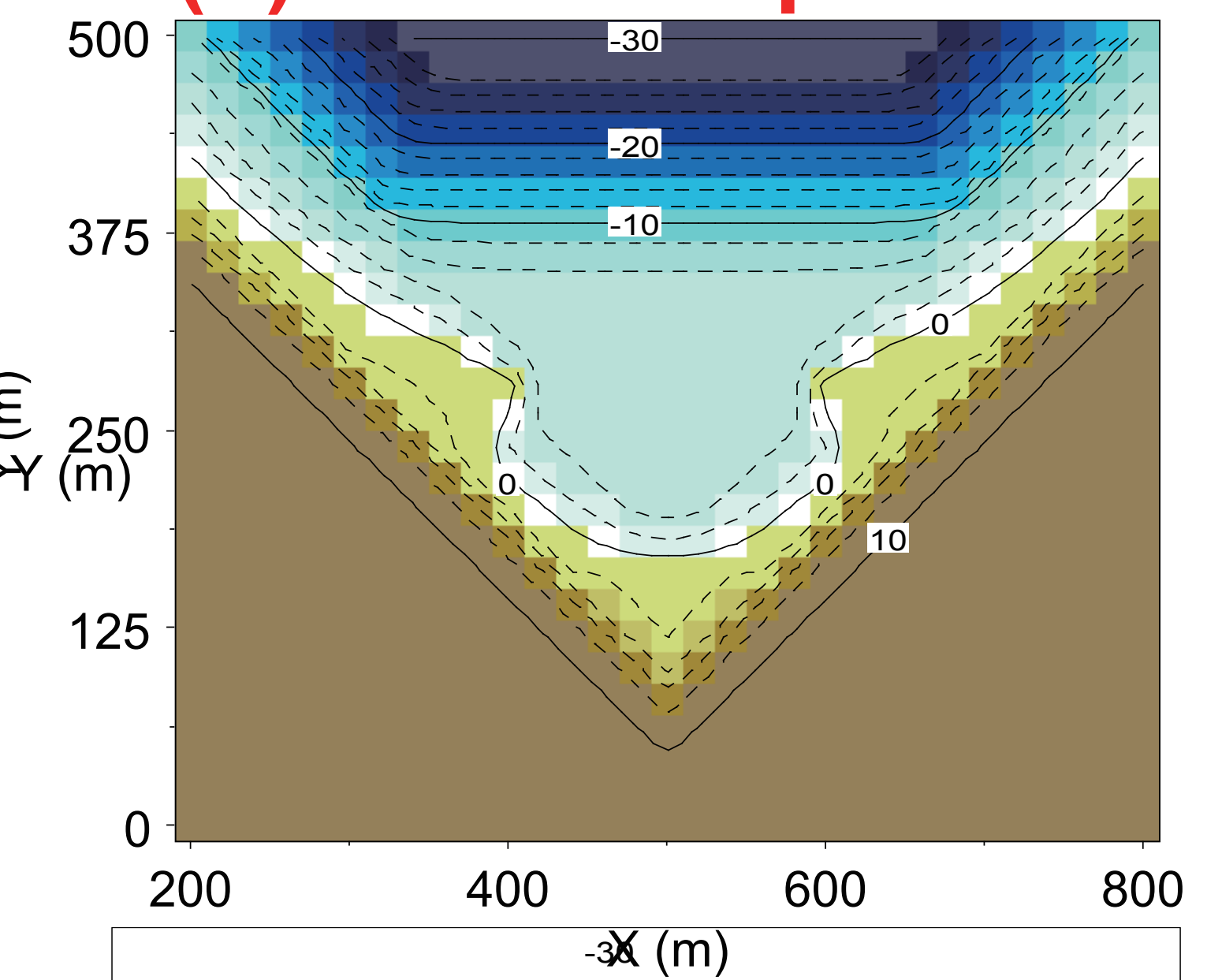

(e) 5000 steps

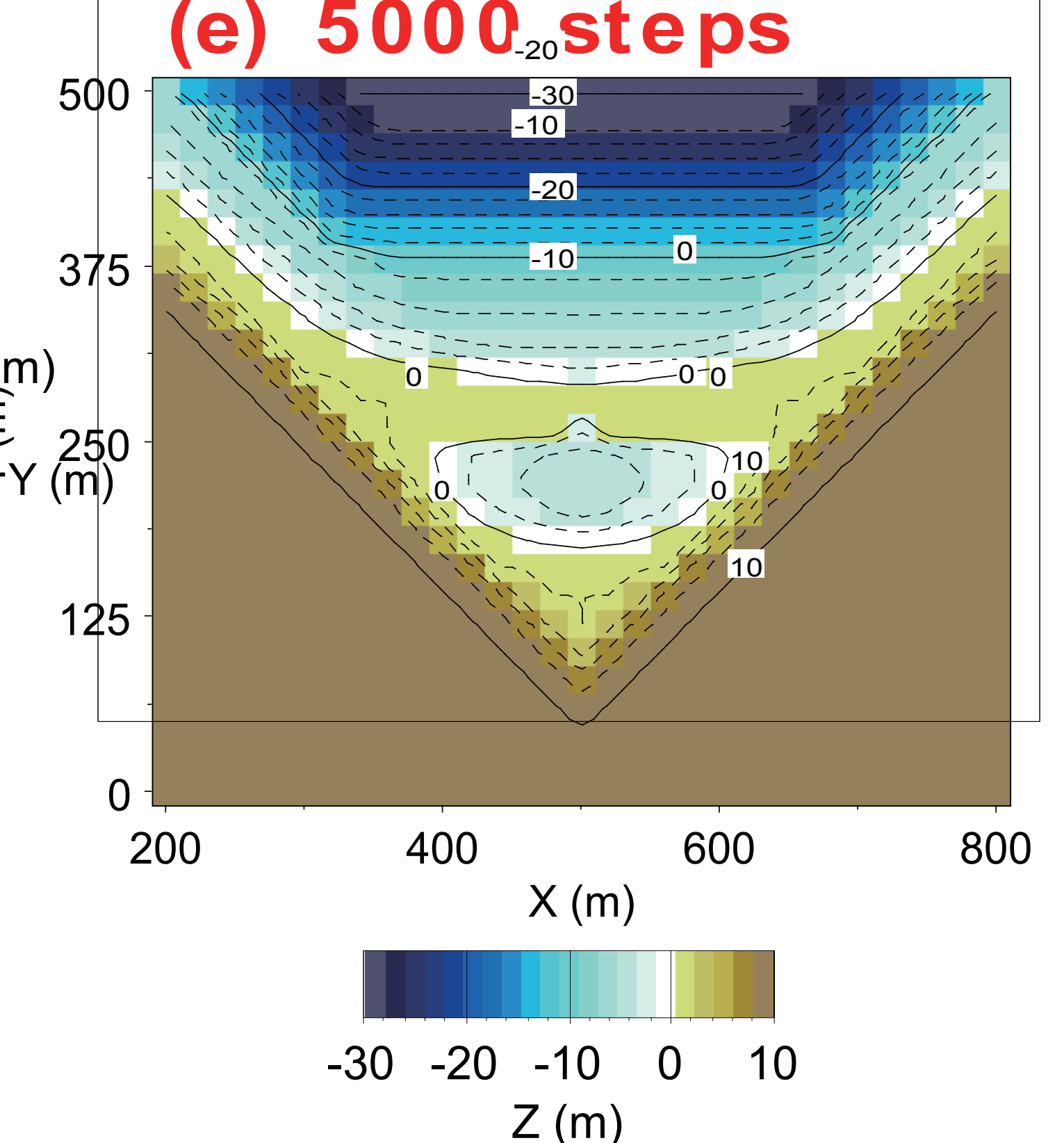

(c) 3000 steps

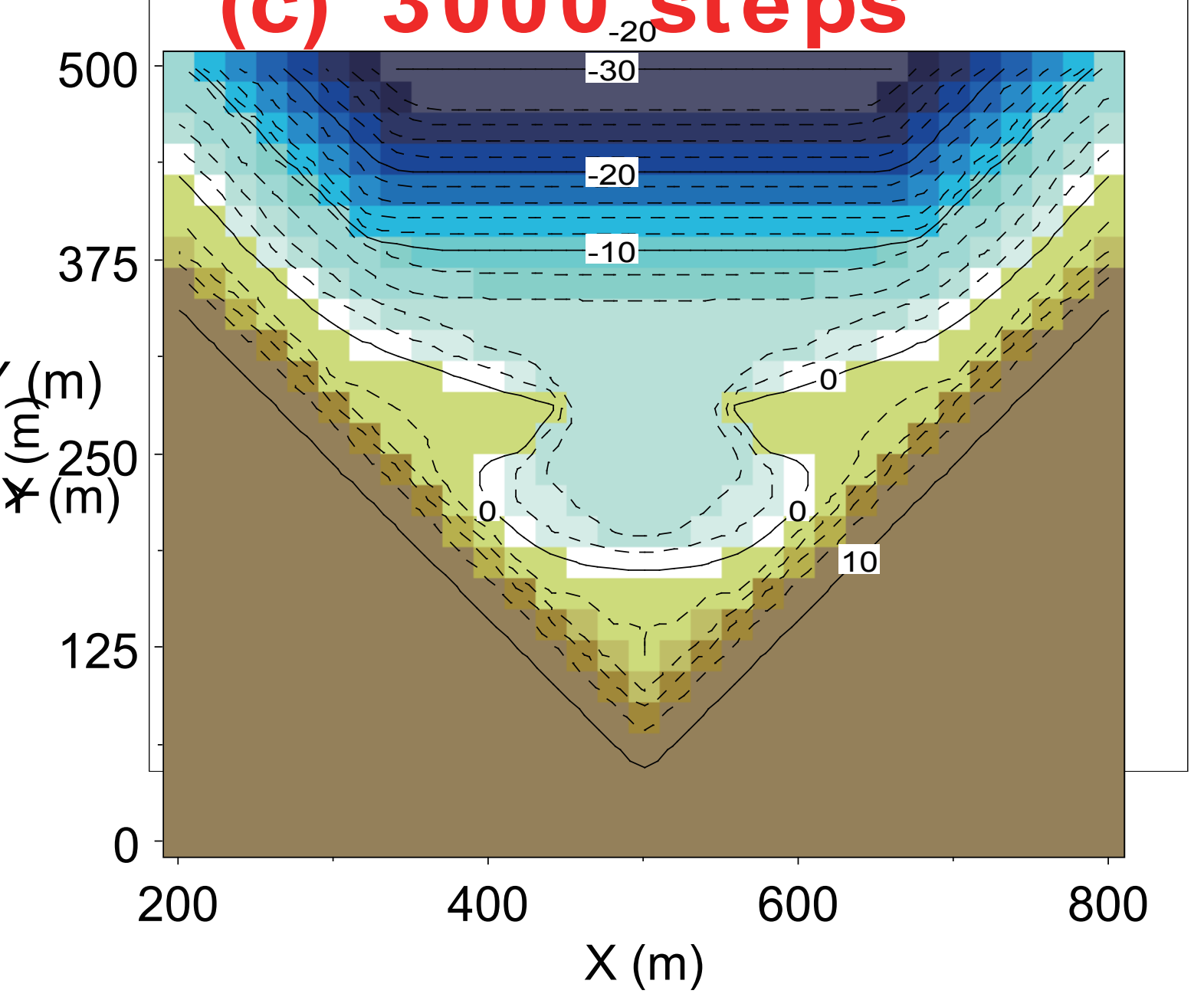

$\begin{array}{cccc}-30 & -20 & -10 & 0 \\ Z(m) & 10\end{array}$

Fig. 3 Predicted results for the development of a bay barrier for the condition equivalent to case 2 in the experiment $\left(h_{s}=5 \mathrm{~cm}\right)$ 